\title{
Cartesian organization in the immediate reproduction of spatial patterns
}

\author{
FRED ATTNEAVE and THOMAS E. CURLEE \\ University of Oregon, Eugene, Oregon 97403
}

Tachistoscopically presented patterns of five and six dots in a circular field were reproduced from immediate memory by 12 subjects. The order of the dots on horizontal and vertical axes was more accurately reproduced than their order on diagonal axes.

In the course of a recent exploratory study, the authors gave two subjects long practice at describing visually presented vectors in terms of both Cartesian and polar coordinates. When two points of light (differentiated by color) were presented on a large screen, the subject judged their relationship either in Cartesian terms, such as "Down 73, Left 45 [millimeters]," or in polar terms, such as "235 [grads, measured clockwise from 12 o'clock], 86 [millimeters]," a grad being one hundredth of a right angle. Cartesian descriptions were easier and more accurate than were polar, even with performance at or near asymptote on both. Latency was about 50\% greater for polar than for Cartesian responses, and, although neither system was clearly better in specifying the length of the vector, the Cartesian was strikingly more accurate in describing its direction; that is, direction was specified by a ratio between judged $\mathrm{X}$ and $\mathrm{Y}$ components with $42 \%$ less error than by a direct angular judgment.

Whatever may be known about "slant detectors" (or hypothesized about "Fourier analyzers") in the visual system, these findings suggest that at some important level the internal representation of spatial relationships depends to a considerable degree upon the use of vertical and horizontal reference axes. In the present experiment, we inquired how such a reference system might affect immediate memory for a pattern of locations in two dimensions. The subjects reproduced dot patterns as quickly as possible after brief exposure, and we determined the relative accuracy with which their reproductions preserved the order of the dots on horizontal and vertical axes vs. diagonal axes.

\section{METHOD}

\section{Subjects}

The subjects were 12 University of Oregon students, 4 male and 8 female. They were paid for their participation.

\section{Stimuli and Apparatus}

Ten basic patterns were generated, half of five and half of six dots. Our aim was to present patterns just within the "appre-

This research was supported by a grant from the National Institute of Mental Health, MH 20449-04, for "Studies on Spatial Representation." hension span," or "subitizing" range; (Woodworth \& Schlosberg, 1954; Kaufman, Lord, Reese, \& Volkmann, 1949), and the results to be reported are quite consistent with the hypothesis that this span is about the same for a reproduction task as for a number-judging task. The patterns were prepared by plotting random coordinates within a $76-\mathrm{mm}$ circle divided into $1-\mathrm{mm}$ matrix units, with the constraints that the shortest distance allowed between any two points was $5 \mathrm{~mm}$ and that no two points in a pattern were allowed to fall within $3 \mathrm{~mm}$ of each other on the $\mathrm{X}$ axis, the $\mathrm{Y}$ axis, or either 45-deg rotation of these axes, so that there were no ties for order in these four directions. They were then transcribed to plain white stimulus cards as patterns of 2-mm black dots in lightly drawn 86- $\mathrm{mm}$ circles; thus, no dot could fall within $5 \mathrm{~mm}$ of the circle in which it was displayed. Ten additional patterns, which were simply 45-deg rotations of the originals, increased the total to 20 .

The stimuli were displayed in a Gerbrands three-field tachistoscope of the 300 series. Each field was masked down with black cardboard to a circular area $86 \mathrm{~mm}$ in diam and viewed at a distance of $82 \mathrm{~cm}$. The subject drew his reproduction in an 86-mm circle on a $14 \times 21.6 \mathrm{~cm}$ paper pad mounted on the tachistoscope just to the right of the eyepiece.

\section{Procedure}

Merely to give the subject some experience viewing dot patterns in the tachistoscope, he was first shown a series of 20 clusters containing various numbers of dots from 3 to 20 and asked to judge the number in each. He was then told that his task would be to reproduce each subsequent pattern, which would contain either five or six dots, as quickly and accurately as he could on the response pad. Each trial went as follows: After hearing a "ready" instruction, the subject pressed a button which initiated a preexposure field lasting $1,500 \mathrm{msec}$ and containing a small fixation mark at the center of the white circle; the dot pattern was then exposed for $300 \mathrm{msec}$ and followed by a blank postexposure field (again a white circle) of $100 \mathrm{msec}$, which was adequate to suppress afterimages. The subject then reproduced the pattern without delay. The five-dot patterns were given first to half the subjects and the six-dot patterns first to the other half; within these blocks the patterns were irregularly arranged.

\section{RESULTS}

In order to score any reproduction, its points had first to be assigned "best" one-to-one correspondences to points in the stimulus pattern. Since an objective method of assignment would have had to employ some goodness-of-match criterion of unknown psychological validity, and in any case would have required an inordinate amount of computing, we contented ourselves 
with subjective matches by two independent judges. Appreciating, however (and, indeed, overrating) the possibility that the correspondences perceived by the judges might themselves be affected by orientation, we took elaborate precautions to prevent this factor from contaminating the results. Each judge established correspondences between every reproduction and its stimulus on two widely separated occasions: On the first, the patterns were oriented as seen by the subject; on the second, they were rotated $45 \mathrm{deg}$. On both occasions the stimulus cards and response sheets were viewed side by side through circular holes in a mask that concealed their edges, and separate copies of the response pattern were labeled on the two occasions. If the four resulting matchings of points ( 2 orientations by 2 judges) were not in perfect agreement, that reproduction was excluded from the data analysis and the same subject's reproduction of the same pattern rotated 45 deg was also dropped, even though it presented no ambiguities of correspondence. Despite this very strict criterion, no reproductions of 5-dot patterns were dropped, and only 20 , or one-sixth, of the 6-dot patterns; moreover, half of these were eliminated for no defect of their own, but because they were 45-deg rotations of ambiguous cases. The clear correspondence between response and stimulus points in the great majority of comparisons gives some indication of the level of performance on the task.

Every surviving reproduction was scored for ordinal accuracy on four different axes: the horizontal, the vertical, and the two 45-deg diagonals. For each axis, an error score was obtained by summating, over all points, the differences in rank between stimulus and reproduction. Horizontal and vertical scores were further summated into an "HV" score; likewise, errors on the two diagonals were summated into a " $D$ " score.

Over all reproductions, the mean HV error was 2.27 and the mean D error was 2.61. This difference was significant $[\mathrm{t}(11)=2.89, \mathrm{p}=.007]$. Horizontal and vertical error scores were almost identical: 1.14 and 1.13 per pattern, respectively. Error was about twice as great on six-dot as on five-dot patterns-certainly more than differential opportunities for error could account forbut there was no indication that the dependence of ordinal accuracy on direction was affected by number of dots.

Overall performance was rather better than the error scores (being sums of rank differences) may suggest: Every reversal of adjacent points (by far the most common error) contributed two, not one, to the error as measured.

\section{DISCUSSION}

Points were ordered more accurately on the horizontal and vertical than on diagonal axes to a significant but modest degree. The difference becomes somewhat more impressive when it is appreciated that geometrical constraints leave only a narrow margin within which differences are possible. For example, whenever the dots were correctly ordered on $\mathrm{X}$ and on $\mathrm{Y}$, freedom to misorder them diagonally was severely limited. Any introduction of metric considerations further limits independence of the measures.

It is well known that numerous and diverse processes of visual perception involve the subjective vertical and horizontal; see Mach (1959), Koffka (1935), Rock (1973), Attneave (1955, 1968), Attneave and Olson (1967), Attneave and Reid (1968), Olson and Attneave (1970), and many others. Thus, it is hardly surprising that Cartesian organization is employed in the shortterm storage of spatial patterns, though we are aware of no previous study that has directly shown this to be the case.

Despite the subjectively picture-like quality of a simple pattern in immediate memory, the use of horizontal-vertical reference axes implies that the visual system has already generated some description of the pattern (Attneave, 1974a, 1974b). The details of the descriptive process are almost entirely a matter for speculation. A very simple hypothesis is that the points are described (at least in part) in dyads or pairs, over some subset of all possible pairs, in terms of vertical and horizontal distances between the points in each pair. In this system, relations such as "a is exactly above b" or "a is directly to the left of b" would have the status of null conditions or anchor points from which deviations would be measured.

\section{REFERENCES}

Attneave. F. Perception of place in a circular field. American Journal of Psychology, 1955, 68, 69-82.

Attneave. F. Triangles as ambiguous figures. American Journal of Psychology, 1968, 81, 447-453.

Atrneave. F. How do you know? American Psychologist, 1974. 29. 493-499. (a)

Attneave, F. Apparent movement and the what-where connection. Psychologia, 1974, 17, 108-120. (b)

Attneave, F., \& Olson, R. K. Discriminability of stimuli varying in physical and retinal orientation. Journal of Experimental Psychology, 1967, 74, 149-157.

Attneave, F.. \& Reid, K. W. Voluntary control of frame of reference and slope equivalence under head rotation. Journal of Experimental Psychology, 1968, 78, 153-159.

Kaufman, E. L., Lord, M. W., Reese, T. W., \& Volkmann, J. The discrimination of visual number. American Journal of Psychology, 1949, 62, 498-525.

KoffKa, K. Principles of Gestalt psychology. New York: Harcourt. Brace. 1935.

MACH, E. The analysis of sensations. New York: Dover, 1959.

Olson, R. K., \& Atrneave, F. What variables produce similarity grouping? American Journal of Psychology, 1970, 83, 1-21.

Rock. I. Orientation and form. New York: Academic Press, 1973. Woodworth. R. S..\& SChlosBerg, H. Experimental psychology. New York: Holt. 1954.

(Received for publication August 19, 1977.) 